\title{
Elephantiasic Pretibial Myxoedema in a Patient with Graves' Disease
}

\author{
Ruzhi Zhang1 ${ }^{*}$, Yuhua Yang1, Wenyuan Zhu ${ }^{2}$ \\ ${ }^{1}$ Department of Dermatology, The Third Affiliated Hospital of Suzhou University, Changzhou, China \\ ${ }^{2}$ Department of Dermatology, The First Affiliated Hospital of Nanjing Medical University, Nanjing, China \\ Email: "zhangruzhi628@163.com
}

Received 18 April 2015; accepted 30 November 2015; published 3 December 2015

Copyright (c) 2015 by authors and Scientific Research Publishing Inc.

This work is licensed under the Creative Commons Attribution International License (CC BY).

http://creativecommons.org/licenses/by/4.0/

(c) (i) Open Access

\begin{abstract}
Pretibial myxoedema (PM) is a late and rare manifestation of autoimmune thyroiditis, particularly in patients with Graves' disease. It occurs in $0.5 \%$ to $4.3 \%$ of patients [1], and is usually associated with high levels of thyroid hormones. The classification of PM includes four forms: non-pitting edema; plaque; nodular; or elephantiasis [1]. Mild PM often regresses spontaneously, but the severe, elephantiasic variant is typically progressive and refractory to treatment. Elephantiasic pretibial myxoedema (EPM) is characterized by massive edema, skin fibrosis and verrucous nodule formation, and it clinically resembles lymphedema. Herein, we describe a man with Graves' disease presenting with EPM for nearly 2 years. Although advanced cases have been described in the literature, to our knowledge, none have reached this level of severity.
\end{abstract}

\section{Keywords}

Pretibial Myxoedema (PM), Graves' Disease

\section{Introduction}

A 57-year-old Chinese man came to our clinic for advice on the cause and management of a severe skin condition of his legs. His lesions had occurred and progressed relentlessly over the past year. There was no obvious pain, but there was occasional pruritus. Once local skin was injured, it needed more than a month to heal. Physical examination revealed nonpitting edema, flesh-colored to erythematous, firm, confluent, polypoid nodules and fissured plaques extending from the shins to the heels of the feet, the dorsa of the left foot and the large toe (Figure 1). Initially, the disorder was thought to be the result of chronic lymphedema. However, his proptosis with eyelid retraction bilaterally reminded us to consider another diagnosis. Questioning the patient revealed that

\footnotetext{
${ }^{*}$ Corresponding author.
}

How to cite this paper: Zhang, R.Z., Yang, Y.H. and Zhu, W.Y. (2015) Elephantiasic Pretibial Myxoedema in a Patient with Graves' Disease. Journal of Cosmetics, Dermatological Sciences and Applications, 5, 297-299. 


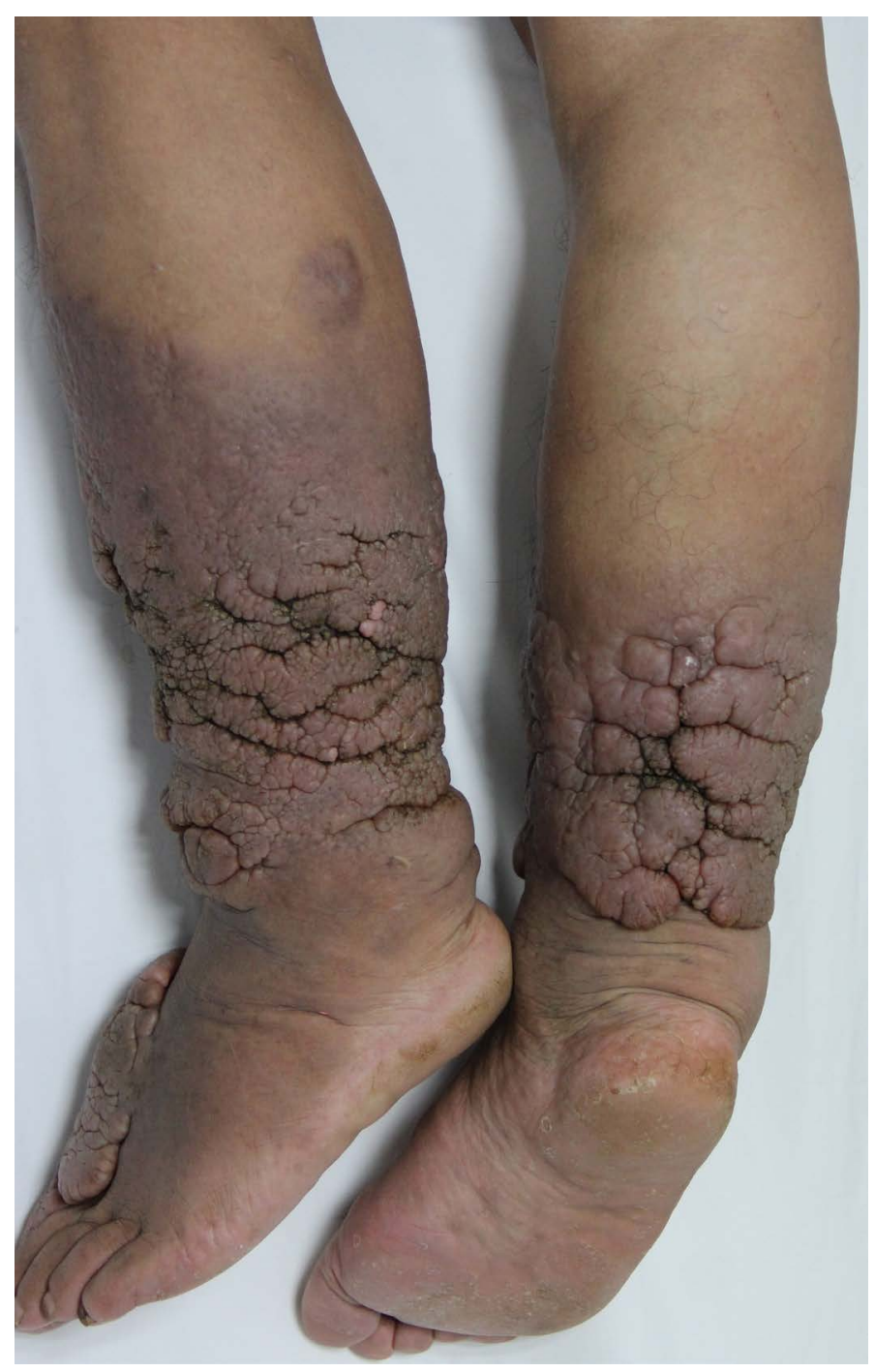

Figure 1. Nonpitting edema, flesh-colored to erythematous, firm, confluent, polypoid nodules and fissured plaques extending from the shins to the heels of the feet, the dorsum of the left foot and large toe.

he had been diagnosed with hyperthyroidism 15 years ago and treated with oral therapy for 6 months (he did not remember the details). A laboratory evaluation revealed: thyrotropin (TSH), $<0.01 \mathrm{IU} / \mathrm{mL}(0.30$ - 5.56); free thyroxine (T4), $31.01 \mathrm{pmol} / \mathrm{L}$ (11.46 - 23.17); free triiodothyronine (T3), $11.95 \mathrm{pmol} / \mathrm{L}$ (2.80 - 7.10); thyroglobulin (TG), $150 \mathrm{mg} / \mathrm{ml}(0.00$ - 85.00); anti-thyroid peroxidase antibody (A-TPO), and $39.60 \mathrm{IU} / \mathrm{ml}(\leq 34)$. The patient looked healthy without evidence of other malignancy or systemic disease. He refused our request for a biopsy. Based on the clinical and laboratory results, EPM in Graves' disease was diagnosed. The patient was referred to the Department of Endocrinology to treat his hyperthyroidism, and then he was lost to follow-up.

\section{Discussion}

The most common presentation of dermopathy in Graves' disease is PM. The time delay from treatment of hyperthyroidism to presentation with localized myxoedema varies from 1 month to 16 years (mean 5.13 years). Clinical features are nonpitting scaly thickening and induration of the skin. In a previous report, among 150 patients with PM, 58\% had nonpitting edema, 20\% had the nodular variant, 21\% had the plaque type, and less than $1 \%$ had either the polypoid or the elephantiasic morphologies [2]. Although several theories have been suggested, the exact pathogenesis of PM remains to be clarified [3]. It was speculated that pretibial fibroblasts may 
react with $\mathrm{T}$ cell lymphocytes via their thyrotropin receptors and then they may overproduce glycosaminoglycans. The content of hyaluronic acid and chondroitin sulfates in the dermis is increased, causing compression of the dermal lymphatics and nonpitting edema. The predilection for localization to the pretibial area may result from trauma with the release of inflammatory cytokines and inflammatory cells or local hypoxia resulting from arterial or venous insufficiency.

The diagnosis of EPM is easily made by clinical findings and histological investigation. Our patient refused a skin biopsy. Thus differential diagnoses, including secondary edema resulting from chronic lymphatic obstruction or venous insufficiency, diabetic dermopathy, lichen amyloidosis and hypertrophic lichen planus were considered. The history of hyperthyroidism and abnormal levels of T3, T4, TG and A-TPO supported the diagnosis. Other systemic examinations excluded diabetes and vascular diseases. Therefore, the final diagnosis was made.

EPM is typically progressive and refractory to treatment. Some therapeutics are effective but are not curative. A potent topical glucocorticoid applied under occlusion is the primary treatment although intralesional steroids are sometimes used. However, local and systemic steroids very rarely give improvement. Other therapeutics have been reported. A 44-year-old woman with Graves' disease and EPM was treated in a trial of multiple recognized therapies, but had a rapid response to rituximab and plasmapheresis [4]. Another patient with PM improved significantly after treatment with ${ }^{131}$ for his Graves' disease [5]. Some authors have reported using complete decongestive physiotherapy [6] or low-dose intravenous immunoglobulins [7] to treat EPM, and have obtained satisfactory results.

\section{Acknowledgements}

The authors are very grateful to Professor V. J. Hearing, Laboratory of Cell Biology, National Cancer Institute, Bethesda, MD, USA, for English-language element of this paper.

\section{References}

[1] Chen, C.T. and Lin, J.C. (2013) Elephantiasic Pretibial Myxoedema. Indian Journal of Medical Research, 137, 568.

[2] Fatourechi, V., Pajouhi, M. and Fransway, A.F. (1994) Dermopathy of Graves Disease (Pretibial Myxedema): Review of 150 Cases. Medicine (Baltimore), 73, 1-7. http://dx.doi.org/10.1097/00005792-199401000-00001

[3] Rapoport, B., Alsabeh, R., Aftergood, D. and McLachlan, S.M. (2000) Elephantiasic Pretibial Myxedema: Insight into and a Hypothesis Regarding the Pathogenesis of the Extrathyroidal Manifestations of Graves' Disease. Thyroid, 10, 685-692. http://dx.doi.org/10.1089/10507250050137761

[4] Heyes, C., Nolan, R., Leahy, M. and Gebauer, K. (2012) Treatment-Resistant Elephantiasic Thyroid Dermopathy Responding to Rituximab and Plasmapheresis. Australasian Journal of Dermatology, 53, e1-e4. http://dx.doi.org/10.1111/j.1440-0960.2010.00693.x

[5] Yu, H., Jiang, X., Pan, M. and Huang, R. (2014) Elephantiasic Pretibial Myxoedema in a Patient with Graves’ Disease That Resolved after ${ }^{131}$ I Treatment. Clinical Nuclear Medicine, 39, 758-759. http://dx.doi.org/10.1097/RLU.0000000000000459

[6] Susser, W.S., Heermans, A.G., Chapman, M.S. and Baughman, R.D. (2002) Elephantiasic Pretibial Myxedema: A Novel Treatment for an Uncommon Disorder. Journal of the American Academy of Dermatology, 46, 723-726. http://dx.doi.org/10.1067/mjd.2002.119655

[7] Dhaille, F., Dadban, A., Meziane, L., Fessier, C., Colta, L., Lok, C., et al. (2012) Elephantiasic Pretibial Myxoedema with Upper-Limb Involvement, Treated with Low-Dose Intravenous Immunoglobulins. Clinical and Experimental Dermatology, 37, 307-308. http://dx.doi.org/10.1111/j.1365-2230.2011.04175.x 